\title{
ALTERAÇÕES NA ESTRUTURA HORIZONTAL, NO PERÍODO DE 2002-2008, EM FLORESTA OMBRÓFILA MISTA NO CENTRO-SUL DO ESTADO DO PARANÁ
}

\author{
CHANGES IN HORIZONTAL STRUCTURE, IN THE PERIOD 2002-2008, IN A MIXED RAIN \\ FOREST IN CENTRAL SOUTHERN PARANA STATE, BRAZIL
}

\author{
Alex Roberto Sawczuk ${ }^{1}$ Afonso Figueiredo Filho ${ }^{2}$ \\ Andrea Nogueira Dias ${ }^{3}$ Luciano Farinha Watzlawick ${ }^{4}$ Thiago Floriani Stepka ${ }^{5}$
}

\begin{abstract}
RESUMO
As alterações na estrutura horizontal de um fragmento de Floresta Ombrófila Mista, localizado na Floresta Nacional de Irati, estado do Paraná, foram avaliadas com dados de medições realizadas nos anos de 2002, 2005 e 2008. A área de estudo possui 25 ha, divididos em 25 parcelas permanentes de 1 ha cada (100 $\mathrm{m} \times 100 \mathrm{~m}$ ). Todos os indivíduos com diâmetro a altura do peito (DAP) igual ou acima de $10 \mathrm{~cm}$ foram mensurados e identificados. Foi analisada a densidade, dominância, frequência, valor de cobertura e valor de importância e para melhor interpretação dos estimadores fitossociológicos e do estágio sucessional da floresta, as espécies foram classificadas em grupos ecofisiológicos: pioneiras, secundárias inicial, secundárias tardias e indeterminadas. Observou-se um decréscimo de 2,3\% no número de indivíduos/ha, sendo encontrados 581 no ano de 2002 e 567 indivíduos/ha em 2008. Em 2008, Ilex paraguariensis foi a espécie com maior número de indivíduos, representando $9,4 \%$ do total. A dominância, avaliada em termos de área basal, alterou-se de 28,6 no ano de 2002 para 30,2 $\mathrm{m}^{2} /$ ha em 2008 , ou seja, houve um acréscimo de 5,1\% no período e a Araucaria angustifolia está sendo a espécie que domina a floresta com $25,9 \%$. A frequência apontou para uma distribuição heterogênea das espécies na floresta, com taxas de $47,4 \%$ no ano de 2002 e 46,3\% em 2008. A Araucaria angustifolia foi a espécie dominante e ecologicamente a mais importante no período com 35,2 (11,7\%) do total do valor de importância absoluto em 2008. De acordo com os estimadores fitossociológicos e grupos ecofisiológicos, a floresta apresenta-se com estoque em crescimento, devido ao incremento em diâmetro nos indivíduos de maiores diâmetros de espécies como Araucaria angustifolia e Ocotea porosa, e em estágio avançado de sucessão ecológica, com a grande maioria das espécies e indivíduos pertencentes às secundárias iniciais e tardias, e a cada ano torna-se mais madura com o ingresso de novas espécies e indivíduos tolerantes à sombra.
\end{abstract}

Palavras-chave: Floresta de Araucária; fitossociologia; dinâmica florestal.

\footnotetext{
ABSTRACT

Changes in the horizontal structure of a fragment of Mixed Rain Forest, located at Irati National Forest, in Parana state, were evaluated by measurements performed during the years 2002, 2005 and 2008. The study area has 25 ha, divided into 25 permanent sample plots of 1 ha $(100 \mathrm{~m} \mathrm{x} 100 \mathrm{~m})$ each. All trees with diameter at $1,30 \mathrm{~m}$ above the ground equal or higher $10 \mathrm{~cm}$ were measured and identified. Density, dominance, frequency, importance value and cover value were analyzed and, to understand better the phytosociological

1 Engenheiro Florestal, Msc., Departamento de Extensão Florestal, Instituto Estadual de Floresta do Estado do Amapá, Av. dos Goitacazes, 1395, Buritizal, CEP 68902-869, Macapá (AP), Brasil. alex.sawczuk@yahoo.com.br

2 Engenheiro Florestal, Dr., Professor Associado do Departamento de Engenharia Florestal, Universidade Estadual do CentroOeste do Paraná, BR 153, Km 7, Bairro Riozinho, Caixa Postal 21, CEP 84500-000, Irati (PR), Brasil. afonso.figueiredo@ pq.cnpq.br

3 Engenheira Florestal, $\mathrm{Dr}^{\mathrm{a}}$, Professora Adjunto do Departamento de Engenharia Florestal, Universidade Estadual do CentroOeste do Paraná, BR 153, Km 7, Bairro Riozinho, Caixa Postal 21, CEP 84500-000, Irati (PR), Brasil. andias@ irati.unicentro.br

4 Engenheiro Florestal, Dr., Professor Adjunto do Departamento de Agronomia, Universidade Estadual do Centro-Oeste do Paraná, Rua PresidenteZacarias, 875, Santa Cruz, Caixa Postal3010,CEP 85015-430, Guarapuava(PR), Brasil. farinha@irati.uni centro.br

5 Engenheiro Florestal, Msc., Doutorando em Engenharia Florestal, Universidade Federal do Paraná, Av. Lothário Meissner, 3400, Jardim Botânico Campus III, CEP 80210-170, Curitiba (PR), Brasil. tfstepka@yahoo.com.br

Recebido para publicação em 1/03/2011 e aceito em 1/04/2013
}

Ci. Fl., v. 24, n. 1, jan.-mar., 2014 
estimators and successional stage of the forest, the species were classified into ecophysiological groups: pioneers, early secondary, late secondary and undetermined. There was a decrease of $2.3 \%$ in the number of individuals per hectare, with 581 recorded in 2002 and 567 individuals/ha in 2008. Currently, Ilex paraguariensis was the species with the greatest number of individuals, representing $9.4 \%$ of the total. The dominance (basal area) changed from 28.6 in 2002 to $30.2 \mathrm{~m}^{2} /$ ha in 2008, i.e., there was an increase of 5.1\% in the period, and currently Araucaria angustifolia has been the species that dominates the forest with $25.9 \%$. The frequency pointed to an uneven distribution of species in the forest, with rates of $47,4 \%$ in 2002 and 46,3\% in 2008. Araucaria angustifolia was the dominant species and the most ecologically important one in the period with $35.2(11.7 \%)$ of the total absolute importance value in 2008. According to the phytosociological estimators and ecophysiological groups the forest still has a growing stock, due to the increment in trees with bigger diameters from species such as Araucaria angustifolia and Ocotea porosa, and is in advanced stage of ecological succession, with the majority of species and individuals belonging to the early and late secondary, and every year it becomes more mature with the ingress of new species and shade tolerant individuals.

Keywords: Araucaria Forest; phytosociology; forest dynamic.

\section{INTRODUÇÃO}

A Floresta Ombrófila Mista, caracterizada pela presença marcante da espécie Araucaria angustifolia, é uma das mais importantes formações florestais da região Sul do Brasil. Possuía originalmente área de $200.000 \mathrm{~km}^{2}$, ocorrendo no Paraná ( $40 \%$ de sua superfície), Santa Catarina (31\%) e Rio Grande do Sul $(25 \%)$ e em manchas esparsas no sul de São Paulo (3\%), internando-se até o sul de Minas Gerais e Rio de Janeiro (1\%). Além disso, inclui-se uma pequena área na província de Missiones, na Argentina (BITTENCOURT et al., 2004) e Paraguai (SILVA et al., 2007).

A exuberância e terras férteis ocupadas pela Floresta Ombrófila Mista no interior do Paraná foram motivações para que colonizadores europeus e migrantes dos estados limítrofes de Santa Catarina e Rio Grande do Sul, nos séculos XIX e XX, promovessem intensa colonização. Este processo foi baseado no extrativismo, onde a floresta era derrubada e substituída, dando origem a cidades e novos ciclos econômicos culturais eram implantados, tais como: café, reflorestamentos e mais recentemente, cana-de-açúcar e soja (SANQUETTA et al., 2001).

Obedecendo a este tipo de ocupação rápido e desordenado da época, o qual foi favorecido pela falta de fiscalização efetiva e escasso estudo sobre a dinâmica dessa formação florestal, necessário ao manejo sustentável, pouco restou da Floresta Ombrófila Mista. Dos 40\% desta formação florestal que cobriam o Estado do Paraná (CARVALHO, 2003), restaram, de acordo com um levantamento realizado pela Fundação de Pesquisas Florestais do Paraná - FUPEF (CASTELLA e BRITEZ, 2004), $0,8 \%$ dessa tipologia florestal em avançado estado de conservação e com alta biodiversidade, possíveis para estudos de acompanhamento fitoecológicos.

Considerando a grande importância ambiental, econômico-social, potencial e complexidade que a Floresta Ombrófila Mista apresenta para a região Sul do país, são fundamentais o estudo e o conhecimento do comportamento de suas características estruturais ao longo do tempo.

Segundo Zin (2005), as informações das alterações na estrutura da floresta podem ser medidas pelos atributos da vegetação, tais como: composição das espécies, no número de árvores, do tamanho das dimensões (área basal) e distribuição espacial, os quais são regidos pelo ingresso, mortalidade e crescimento de indivíduos e espécies vegetais.

Para Scolforo (1993), as informações das alterações da estrutura servem como base para manter a diversidade florística, observar os aspectos autoecológicos e sinecológicos das espécies, detectar o estádio sucessional e subsidiar planos de revegetação e manejo florestal sustentado.

Devido à importância que a Floresta Ombrófila Mista tem para a região sul do Brasil, várias pesquisas têm sido conduzidas no sentido de estudar e avaliar a estrutura horizontal e suas alterações (dinâmica), podendo-se mencionar os seguintes estudos realizados dessa tipologia florestal: Sawczuk (2009), Rode (2008), Moscovich (2006), Formento et al. (2004), Barth Filho (2002), Sanquetta et al. (2001), Schaaf (2001), Pizatto (1999), Durigan (1999), entre outros. 
Neste sentido, este trabalho estudou e comparou as alterações na densidade, dominância, frequência e valor de importância, ocorridas na comunidade, no período de 2002 a 2008, de acordo com os grupos ecofisiológicos das espécies com o objetivo principal de contribuir com informações que possam ser empregadas no manejo sustentável e conservação desta importante tipologia florestal para o Sul do Brasil.

\section{MATERIAIS E MÉTODOS}

\section{Área de estudo e base de dados}

A área de estudo está na Floresta Nacional de Irati (FLONA de Irati), que está inserida no Segundo Planalto Paranaense, zona fisiográfica de Irati, paralelo $25^{\circ} 27^{\prime} 56^{\prime \prime}$ de latitude Sul, com interseção com o meridiano $50^{\circ} 37^{\prime} 51^{\prime \prime}$ de longitude Oeste a uma altitude média de 820 metros acima do nível do mar. Tem relevo suave ondulado, no âmbito dos municípios de Fernandes Pinheiro e Teixeira Soares, estado do Paraná (MAZZA et al., 2005).

Segundo a classificação climática de Köppen, o clima de Irati é tipo $\mathrm{Cfb}$ - temperado, ou seja, Subtropical Úmido Mesotérmico, caracterizado por verões frescos, geadas severas e frequentes e sem estação seca (MAZZA et al., 2005). As médias mensais de precipitação pluviométrica e umidade relativa do ar são 193,97 mm e 79,58\%, respectivamente, com temperaturas média máxima de $24,2^{\circ} \mathrm{C}$ e a média mínima de $11^{\circ} \mathrm{C}$ (FIGUEIREDO FILHO et al., 2006).

Para Mazza et al. (2005), a Floresta Nacional de Irati apresenta um mosaico de formações geológicas do Paleozoico relacionadas aos grupos Depósitos Quaternários, Guatá e Passa Dois. A área de estudo está localizada nas formações Guatá e Passa Dois, na sua maioria.

O Bioma Mata Atlântica ocupa 98\% do Estado do Paraná e a formação florestal que compõe a região da Floresta Nacional de Irati é a Floresta Ombrófila Mista Montana tendo como principal espécie a Araucaria angustifolia associada com a Ocotea porosa, formando agrupamentos característicos (IBGE, 1992; IBGE, 2010).

Os dados foram coletados em 25 parcelas permanentes com área de 1 ha $(100 \mathrm{~m}$ x $100 \mathrm{~m})$ cada, instaladas e medidas em 2002 pelo Departamento de Engenharia Florestal da UNICENTRO em um fragmento de Floresta Ombrófila Mista com 1273 ha, existente na FLONA de Irati, o qual sofreu exploração seletiva no passado, todavia, há mais de 60 anos se encontra conservado e protegido, constituindo-se em local sem similar para pesquisas da tipologia.

As parcelas foram remedidas em 2005 e 2008 e em todas as ocasiões foram medidos todos os indivíduos arbóreos com diâmetros (DAP) iguais ou acima de $10 \mathrm{~cm}$, tendo sido numerados, identificados e posicionados em um sistema cartesiano (X,Y). Nas remedições, foram registradas as árvores mortas e as que ingressaram. A identificação botânica seguiu o Sistema de Classificação APG II (Angiosperm Phylogeny Group II), que foi utilizado por Souza e Lorenzi (2005).

\section{Análise de dados}

Os dados das amostragens sucessivas foram avaliados pelos seguintes estimadores fitossociológicos: densidade, dominância, frequência e valor de importância. Os valores relativos e absolutos destas variáveis foram calculados e analisados considerando a área amostrada (25 ha), sendo a frequência obtida por parcela $(100 \mathrm{~m} \mathrm{x}$ $100 \mathrm{~m}$ ), para os anos de medição de 2002, 2005 e 2008. Os cálculos foram realizados utilizando-se do suplemento FlorExel versão 3.1.2 (ARCE, 2007).

Para melhor interpretação das estimativas fitossociológicas e do estádio sucessional da floresta, as espécies foram classificadas em grupos ecofisiológicos, baseando-se nos trabalhos realizados por Gandolfi et al. (1995) que separaram as espécies em quatro categorias sucessionais: a) pioneiras - espécies de ciclo de vida curta completado sob condições de pleno sol para estabelecimento e reprodução; b) secundárias iniciais - espécies que precisam de plena luz para crescimento e reprodução; c) secundárias tardias - consideradas aquelas espécies longevas, que crescem à sombra, mas necessitam de plena luz para reprodução; d) sem caracterização (indeterminadas) - em função da carência de informações, não puderam ser enquadradas em nenhuma das categorias anteriores.

As informações ecofisiológicas das espécies foram obtidas em publicações de Catharino et al. (2006), Mantovani et al. (2005), Santos et al. (2004), Isernhagen et al. (2001), Oliveira et al. (2001), Fonseca e Rodrigues (2000), dentre outros.

Dessa forma, estabeleceram-se as seguintes hipóteses: 
a) O estágio sucessional afeta a estrutura da floresta; b) A floresta em estágio sucessional avançado favorece o aumento da riqueza e estabilidade do ecossistema.

\section{RESULTADOS E DISCUSSÃO}

\section{Estrutura horizontal}

Os resultados da análise da estrutura horizontal para os anos de 2002, 2005 e 2008 das 30 espécies de maior valor de importância absoluto (VI $a b s$.) estão listados em ordem decrescente na Tabela1.

\section{Densidade}

$\mathrm{O}$ número total de árvores na floresta decresceu, com uma taxa de mortalidade de $2,3 \%(-0,39 \% /$ ano $)$ no período, alterando de 581 indivíduos por hectare no ano de 2002 para $567 \mathrm{em}$ 2008. Estas árvores, com DAP igual ou superior a $10 \mathrm{~cm}$, estavam divididas em 112 e 117 espécies pertencentes a 44 famílias botânicas. Os resultados de densidade deste e de outros trabalhos podem ser observados na Tabela 2.

A redução de $2,3 \%$ ocorreu nas classes de menores diâmetros, sendo justificada pela alta mortalidade de indivíduos das espécies Ilex paraguariensis (-6,9 árvores/ha), Myrsine umbellata (-3,8 árvores/ha), Casearia decandra (-2,4 árvores/ ha), Matayba elaegnoides (-2,4 árvores/ha) e Prunus brasiliensis (-2,3 árvores/ha). Essa mortalidade de indivíduos, principalmente da Ilex paraguariensis (diminuiu de 60,2 para 53,4 árvores por hectare no período de 6 anos), indica que esta espécie tende a perder sua posição de importância na floresta para a espécie Ocotea odorifera (aumentou de 51,9 para 52,6 árvores por hectare) e já tem iguais valores de importância ( $\mathrm{VI}=16,3)$ em 2008. Os fatores, além da competição intra e interespecífica, que podem ter ocasionado essa mortalidade, são o envelhecimento e a dominância exercida pelos indivíduos de Araucaria angustifolia e Ocotea porosa que aumentaram seus diâmetros no período.

Uma característica observada na FOM é que apesar da riqueza de espécies e famílias botânicas poucas delas detêm a grande maioria dos indivíduos arbóreos da comunidade e assim, caracterizam a fitofisionomia desta tipologia florestal. Observou-se que as 20 espécies mais abundantes englobavam 78,3 e $77,5 \%$ do total de indivíduos no período 2002-2008, sendo que as espécies Ilex paraguarienses, Ocotea odorifera, Araucaria angustifolia, Nectandra grandiflora e Casearia decandra representavam 39,2 e 38,3\% do total de indivíduos por hectare. Por outro lado, $97 \%$ dos indivíduos registrados nos anos de medição pertenciam a 20 famílias (45,5\% do total de famílias), sendo Lauraceae com 26,8 e 27,1\%, Aquifoliaceae com 13,0 e 11,7\%, Salicaceae com 9,6 e 9,9\%, Myrtaceae com 7,7 e 9,3\% e Araucariaceae com 7,3 e $7,5 \%$ as cinco famílias mais densas. Isto se deve ao grande número de espécies nestas famílias botânicas, exceto na Araucariaceae.

A análise ecofisiológica mostrou uma tendência de avanço no estádio sucessional da floresta, onde do total de indivíduos registrados no período, 59,9 e 60,8\% deles pertenciam ao grupo ecofisiológico das secundárias tardias, 29,3 e $28,8 \%$ ao grupo das secundárias iniciais, 7,2 e $6,3 \%$ ao grupo das pioneiras e 3,5 e $4,1 \%$ do grupo denominado de indeterminadas. As espécies que mais ingressaram e contribuíram para isso foram: Coussarea contracta (5,1 árvores/ha), Myrciaria floribunda (2,6), Eugenia involucrata $(2,1)$, Casearia sylvestris (1,9) e Myrcia hebepetala $(1,8)$. Estas espécies secundárias, reguladas pela luminosidade, ocupam o estrato inferior e médio da floresta mostrando assim que a floresta se encontra em estado avançado de sucessão (floresta madura), com os estratos bem definidos, a qual fornece condições para regeneração desses indivíduos tolerantes à sombra (Lamprecht, 1990).

Observou-se ainda, um baixo ingresso de indivíduos de Araucaria angustifolia na comunidade, com apenas 0,2 indivíduo por hectare nos seis anos de monitoramento, ou seja, 5 indivíduos nos 25 hectares, mostrando a necessidade de manejo florestal, a fim de viabilizar a perpetuação da espécie.

\section{Dominância}

Apesar da mortalidade de indivíduos (densidade total) na comunidade, esta apresentou um ganho em área basal (dominância total). Este crescimento em área basal foi de $1,5 \mathrm{~m}^{2} /$ ha, passando de $28,7 \mathrm{~m}^{2} / \mathrm{ha}$ no ano de 2002 para $30,2 \mathrm{~m}^{2} / \mathrm{ha} \mathrm{em}$ 2008. Este acréscimo de 5,2\% (0,87\%/ano) está abaixo de outras pesquisas conforme a Tabela 3 .

O incremento de 4,24\%/ano observado por Formento (2004) pode estar relacionado ao tamanho das unidades amostrais, o qual pode não 
TABELA 1: Estimadores fitossociológicos da estrutura horizontal para os anos de 2002, 2005 e 2008 , do fragmento de Floresta Ombrófila Mista, na Floresta Nacional de Irati, estado do Paraná.

TABLE 1: Phytosociological estimators of horizontal structure for the years of 2002, 2005 and 2008, found in the remnant of Mixed Rain Forest, at the National Forest of Irati, in Paraná state.

\begin{tabular}{|c|c|c|c|c|c|c|c|c|c|c|c|c|c|c|c|c|c|c|c|c|c|c|}
\hline & DA & DA & DA & DoA & DoA & DoA & FAi & FAi & FAi & DRi & DRi & DRi & DoRi & DoRi & DoRi & FRi & FRi & FRi & $\begin{array}{l}\mathrm{VI} \\
(a b s .) \\
\end{array}$ & $\begin{array}{l}\text { VI } \\
(a b s) .\end{array}$ & $\begin{array}{l}\text { VI } \\
(a b s) .\end{array}$ & Grupo \\
\hline Espécie & 2002 & 2005 & 2008 & 2002 & 2005 & 2008 & 2002 & 2005 & 2008 & 2002 & 2005 & 2008 & 2002 & 2005 & 2008 & 2002 & 2005 & 2008 & 2002 & & 2008 & $\begin{array}{l}\text { Ecofi- } \\
\text { sioló- } \\
\text { gico }\end{array}$ \\
\hline $\begin{array}{l}\text { Araucaria } \\
\text { angustifolia } \\
\text { (Bertol.) Kuntze }\end{array}$ & 42,1 & 42,2 & 42,3 & 7,1 & 7,6 & 7,8 & 100 & 100 & 100 & 7,3 & 7,4 & 7,5 & 24,6 & 25,4 & 25,9 & 1,9 & 1,9 & 1,9 & 33,8 & & 35,2 & St \\
\hline $\begin{array}{l}\text { Ilex } \\
\text { paraguariensis } \\
\text { A. St.-Hil. }\end{array}$ & 60,2 & 56,0 & 53,4 & 1,6 & 1,6 & 1,5 & 100 & 100 & 100 & 10,4 & 9,8 & 9,4 & 5,6 & 5,3 & 5,1 & 1,9 & 1,9 & 1,9 & 17,9 & & 16,3 & St \\
\hline $\begin{array}{l}\text { Ocotea odorifera } \\
\text { (Vellozo) } \\
\text { Rohwer }\end{array}$ & 51,9 & 52,4 & 52,6 & 1,5 & 1,6 & 1,6 & 88 & 88 & 88 & 8,9 & 9,2 & 9,3 & 5,2 & 5,4 & 5,4 & 1,7 & 1,6 & 1,6 & 15,8 & & 16,3 & St \\
\hline $\begin{array}{l}\text { Nectandra } \\
\text { grandiflora Nees }\end{array}$ & 37,6 & 36,8 & 35,4 & 1,8 & 1,9 & 1,9 & 100 & 100 & 100 & 6,5 & 6,4 & 6,2 & 6,3 & 6,3 & 6,3 & 1,9 & 1,9 & 1,9 & 14,7 & & 14,3 & St \\
\hline $\begin{array}{l}\text { Ocotea porosa } \\
\text { (Nees) Barroso }\end{array}$ & 19,4 & 19,2 & 19,2 & 2,5 & 2,7 & 2,8 & 88 & 88 & 88 & 3,3 & 3,4 & 3,4 & 8,7 & 8,9 & 9,2 & 1,7 & 1,6 & 1,6 & 13,7 & & 14,2 & St \\
\hline $\begin{array}{l}\text { Casearia } \\
\text { decandra Jacq. }\end{array}$ & 36,0 & 34,3 & 33,6 & 0,8 & 0,8 & 0,8 & 100 & 100 & 100 & 6,2 & 6,0 & 5,9 & 2,7 & 2,6 & 2,6 & 1,9 & 1,9 & 1,9 & 10,8 & & 10,4 & $\mathrm{Si}$ \\
\hline $\begin{array}{l}\text { Cedrela fissilis } \\
\text { Vell. }\end{array}$ & 15,4 & 15,2 & 15,1 & 1,3 & 1,4 & 1,5 & 100 & 100 & 100 & 2,7 & 2,7 & 2,7 & 4,6 & 4,7 & 4,8 & 1,9 & 1,9 & 1,9 & 9,2 & 9,2 & 9,4 & $\mathrm{Si}$ \\
\hline $\begin{array}{l}\text { Ocotea puberula } \\
\text { (Rich.) Nees }\end{array}$ & 14,1 & 13,6 & 13,2 & 1,4 & 1,5 & 1,5 & 100 & 100 & 100 & 2,4 & 2,4 & 2,3 & 5,0 & 4,9 & 4,8 & 1,9 & 1,9 & 1,9 & 9,3 & 9,1 & 9,0 & St \\
\hline $\begin{array}{l}\text { Matayba } \\
\text { elaeagnoides } \\
\text { Radlk. }\end{array}$ & 18,2 & 17,1 & 15,8 & 1,2 & 1,2 & 1,1 & 92 & 92 & 92 & 3,1 & 3,0 & 2,8 & 4,1 & 4,0 & 3,8 & 1,7 & 1,7 & 1,7 & 9,0 & 8,7 & 8,3 & $\mathrm{Si}$ \\
\hline $\begin{array}{l}\text { Nectandra } \\
\text { megapotamica } \\
\text { (Spreng.) Mez }\end{array}$ & 17,2 & 17,4 & 17,7 & 0,9 & 1,0 & 1,0 & 96 & 96 & 100 & 3,0 & 3,0 & 3,1 & 3,2 & 3,3 & 3,3 & 1,8 & 1,8 & 1,9 & 8,0 & 8,1 & 8,3 & St \\
\hline $\begin{array}{l}\text { Syagrus } \\
\text { romanzoffiana } \\
\text { (Cham.) } \\
\text { Glassman }\end{array}$ & 18,0 & 18,1 & 17,8 & 0,7 & 0,8 & 0,8 & 96 & 96 & 96 & 3,1 & 3,2 & 3,2 & 2,6 & 2,5 & 2,5 & 1,8 & 1,8 & 1,8 & 7,5 & 7,5 & 7,4 & $\mathrm{Si}$ \\
\hline $\begin{array}{l}\text { Coussarea } \\
\text { contracta (Walp.) } \\
\text { Müll.Arg. }\end{array}$ & 19,9 & 22,2 & 25,0 & 0,3 & 0,3 & 0,4 & 88 & 92 & 100 & 3,4 & 3,9 & 4,4 & 0,9 & 1,1 & 1,2 & 1,7 & 1,7 & 1,9 & 6,0 & 6,7 & 7,4 & St \\
\hline $\begin{array}{l}\text { Myrsine } \\
\text { umbellata Mart. }\end{array}$ & 23,3 & 21,8 & 19,4 & 0,5 & 0,5 & 0,4 & 100 & 100 & 100 & 4,0 & 3,8 & 3,4 & 1,8 & 1,6 & 1,4 & 1,9 & 1,9 & 1,9 & 7,7 & 7,3 & 6,7 & $\mathrm{Si}$ \\
\hline $\begin{array}{l}\text { Cinnamodendron } \\
\text { dinisii Schwacke }\end{array}$ & 14,5 & 13,5 & 12,7 & 0,7 & 0,7 & 0,6 & 96 & 96 & 96 & 2,5 & 2,4 & 2,2 & 2,4 & 2,2 & 2,1 & 1,8 & 1,8 & 1,8 & 6,7 & 6,4 & 6,1 & $\mathrm{P}$ \\
\hline $\begin{array}{l}\text { Ocotea } \\
\text { diospyrifolia } \\
\text { (Meisn.) Mez }\end{array}$ & 9,1 & 9,0 & 8,9 & 0,7 & 0,8 & 0,8 & 100 & 100 & 96 & 1,6 & 1,6 & 1,6 & 2,4 & 2,5 & 2,5 & 1,9 & 1,9 & 1,8 & 5,9 & 5,9 & 5,9 & St \\
\hline $\begin{array}{l}\text { Casearia } \\
\text { sylvestris Sw. }\end{array}$ & 12,3 & 13,2 & 14,2 & 0,3 & 0,3 & 0,3 & 88 & 92 & 96 & 2,1 & 2,3 & 2,5 & 0,9 & 1,0 & 1,1 & 1,7 & 1,7 & 1,8 & 4,7 & 5,0 & 5,3 & $\mathrm{Si}$ \\
\hline $\begin{array}{l}\text { Prunus } \\
\text { brasiliensis } \\
\text { (Cham. \& } \\
\text { Schltdl.) D. Dietr }\end{array}$ & 13,2 & 12,0 & 10,9 & 0,4 & 0,3 & 0,3 & 100 & 100 & 100 & 2,3 & 2,1 & 1,9 & 1,3 & 1,1 & 1,0 & 1,9 & 1,9 & 1,9 & 5,5 & 5,1 & 4,7 & $\mathrm{Si}$ \\
\hline $\begin{array}{l}\text { Ilex theezans } \\
\text { Mart. ex Reissek }\end{array}$ & 12,8 & 12,2 & 11,4 & 0,3 & 0,3 & 0,3 & 100 & 100 & 100 & 2,2 & 2,1 & 2,0 & 0,9 & 0,9 & 0,8 & 1,9 & 1,9 & 1,9 & 5,0 & 4,9 & 4,7 & $\mathrm{Si}$ \\
\hline $\begin{array}{l}\text { Dalbergia } \\
\text { frutescens (Vell.) } \\
\text { Britton }\end{array}$ & 9,8 & 9,8 & 9,4 & 0,3 & 0,3 & 0,3 & 100 & 100 & 100 & 1,7 & 1,7 & 1,7 & 0,9 & 0,9 & 0,9 & 1,9 & 1,9 & 1,9 & 4,5 & 4,5 & 4,4 & $\mathrm{Si}$ \\
\hline $\begin{array}{l}\text { Myrcia hebe- } \\
\text { petala DC. }\end{array}$ & 9,5 & 10,1 & 11,4 & 0,1 & 0,2 & 0,2 & 100 & 100 & 100 & 1,6 & 1,8 & 2,0 & 0,5 & 0,5 & 0,6 & 1,9 & 1,9 & 1,9 & 4,0 & 4,1 & 4,4 & Id \\
\hline $\begin{array}{l}\text { Campomanesia } \\
\text { xanthocarpa } \mathrm{O} \text {. } \\
\text { Berg }\end{array}$ & 6,1 & 6,3 & 6,5 & 0,3 & 0,3 & 0,4 & 96 & 100 & 100 & 1,1 & 1,1 & 1,1 & 1,1 & 1,1 & 1,2 & 1,8 & 1,9 & 1,9 & 3,9 & 4,1 & 4,2 & St \\
\hline $\begin{array}{l}\text { Eugenia } \\
\text { involucrata DC. }\end{array}$ & 6,2 & 6,8 & 8,2 & 0,1 & 0,2 & 0,2 & 92 & 92 & 100 & 1,1 & 1,2 & 1,5 & 0,5 & 0,5 & 0,6 & 1,7 & 1,7 & 1,9 & 3,3 & 3,4 & 3,9 & St \\
\hline $\begin{array}{l}\text { Myrciaria } \\
\text { floribunda (West } \\
\text { ex Willd.) O. } \\
\text { Berg }\end{array}$ & 6,3 & 7,8 & 9,0 & 0,1 & 0,1 & 0,1 & 92 & 92 & 92 & 1,1 & 1,4 & 1,6 & 0,3 & 0,4 & 0,4 & 1,7 & 1,7 & 1,7 & 3,2 & 3,5 & 3,7 & St \\
\hline $\begin{array}{l}\text { Myrcia rostrata } \\
\text { DC. }\end{array}$ & 8,8 & 8,7 & 8,7 & 0,1 & 0,2 & 0,1 & 96 & 96 & 92 & 1,5 & 1,5 & 1,5 & 0,5 & 0,5 & 0,5 & 1,8 & 1,8 & 1,7 & 3,8 & 3,8 & 3,7 & $\mathrm{P}$ \\
\hline
\end{tabular}

Continua ... 
TABELA 1: Continuação ...

TABLE 1: Continued ...

\begin{tabular}{|c|c|c|c|c|c|c|c|c|c|c|c|c|c|c|c|c|c|c|c|c|c|c|}
\hline & DA & DA & DA & DoA & DoA & DoA & FAi & FAi & FAi & DRi & DRi & DRi & DoRi & DoRi & DoRi & FRi & FRi & FRi & $\begin{array}{l}\mathrm{VI} \\
\text { (abs. })\end{array}$ & $\begin{array}{c}\mathrm{VI} \\
\text { (abs). }\end{array}$ & $\begin{array}{l}\mathrm{VI} \\
(a b s) .\end{array}$ & Grupo \\
\hline Espécie & 2002 & 2005 & 2008 & 2002 & 2005 & 2008 & 2002 & 2005 & 2008 & 2002 & 2005 & 2008 & 2002 & 2005 & 2008 & 2002 & 2005 & 2008 & 2002 & 2005 & 2008 & $\begin{array}{l}\text { Ecofi- } \\
\text { siolo- } \\
\text { gico }\end{array}$ \\
\hline $\begin{array}{l}\text { Psychotria vel- } \\
\text { losiana Berth. }\end{array}$ & 5,3 & 5,1 & 5,4 & 0,2 & 0,2 & 0,2 & 100 & 96 & 100 & 0,9 & 0,9 & 1,0 & 0,6 & 0,7 & 0,7 & 1,9 & 1,8 & 1,9 & 3,4 & 3,4 & 3,5 & St \\
\hline $\begin{array}{l}\text { Clethra scabra } \\
\text { Pers. }\end{array}$ & 5,3 & 4,9 & 4,3 & 0,3 & 0,3 & 0,3 & 92 & 92 & 84 & 0,9 & 0,9 & 0,8 & 1,1 & 1,1 & 0,9 & 1,7 & 1,7 & 1,6 & 3,8 & 3,6 & 3,3 & $\mathrm{P}$ \\
\hline $\begin{array}{l}\text { Sloanea mono- } \\
\text { sperma Vell. }\end{array}$ & 5,0 & 4,6 & 4,4 & 0,2 & 0,3 & 0,2 & 88 & 88 & 88 & 0,9 & 0,8 & 0,8 & 0,8 & 0,8 & 0,8 & 1,7 & 1,6 & 1,6 & 3,4 & 3,3 & 3,2 & St \\
\hline $\begin{array}{l}\text { Allophylus edulis } \\
\text { (A. St.-Hil., } \\
\text { Cambess. \& A. } \\
\text { Juss.) Rad }\end{array}$ & 4,9 & 5,8 & 6,3 & 0,1 & 0,1 & 0,1 & 84 & 88 & 92 & 0,9 & 1,0 & 1,1 & 0,3 & 0,3 & 0,3 & 1,6 & 1,6 & 1,7 & 2,7 & 3,0 & 3,2 & $\mathrm{Si}$ \\
\hline $\begin{array}{l}\text { Mosiera prismat- } \\
\text { ica (D. Legrand) } \\
\text { Landrum }\end{array}$ & 4,5 & 4,8 & 4,9 & 0,1 & 0,1 & 0,1 & 96 & 96 & 100 & 0,8 & 0,8 & 0,9 & 0,3 & 0,3 & 0,3 & 1,8 & 1,8 & 1,9 & 2,8 & 2,9 & 3,0 & Id \\
\hline $\begin{array}{l}\text { Chrysophyllum } \\
\text { gonocarpum } \\
\text { (Mart. \& } \\
\text { Eichler.) Engl. }\end{array}$ & 3,6 & 3,9 & 3,9 & 0,1 & 0,1 & 0,1 & 80 & 84 & 84 & 0,6 & 0,7 & 0,7 & 0,3 & 0,3 & 0,4 & 1,5 & 1,6 & 1,6 & 2,4 & 2,6 & 2,6 & $\mathrm{St}$ \\
\hline$\ldots$ & $\ldots$ & $\ldots$ & $\ldots$ & $\ldots$ & $\ldots$ & $\ldots$ & $\ldots$ & $\ldots$ & $\ldots$ & $\ldots$ & $\ldots$ & $\ldots$ & $\ldots$ & $\ldots$ & $\ldots$ & $\ldots$ & $\ldots$ & $\ldots$ & $\ldots$ & $\ldots$ & $\ldots$ & $\ldots$ \\
\hline Total & 581 & 572 & 567 & 28,7 & 29,9 & 30,2 & 5304 & 5364 & 5412 & 100 & 100 & 100 & 100 & 100 & 100 & 100 & 100 & 100 & 300 & 300 & 300 & 117 \\
\hline
\end{tabular}

ter representado os parâmetros da população e ao estádio sucessional da floresta. Segundo o autor, a floresta pode ser classificada como primária alterada, onde houve coleta seletiva de madeira em décadas passadas, o que contribui para alto incremento de indivíduos de Lithraea brasiliense e Matayba elaeagnoides no período estudado.

Já o crescimento periódico em área basal observado no fragmento de Irati aponta para uma floresta com árvores mais grossas (de maiores diâmetros), ocupando mais espaços e menos densas (poucas árvores). No período estudado, o diâmetro médio da comunidade passoude $25,1 \mathrm{~cm}$ para $26,0 \mathrm{~cm}$.

Quanto às espécies dominantes pouco mudou, sendo a Araucaria angustifolia e a Ocotea porosa as espécies que possuem a maior área basal. Os indivíduos dessas duas espécies não estão em maior número na comunidade, porém, apresentam maiores diâmetros, com diâmetros médios quadráticos de $48,5 \mathrm{~cm}$ e $43,1 \mathrm{~cm}$, respectivamente, para o ano de 2008.

Os resultados revelam que poucas espécies e famílias botânicas dominam em termos de área basal essa tipologia florestal. As cinco espécies com maior área basal neste estudo foram: Araucaria angustifolia, Ocotea porosa, Nectandra grandiflora, Ilex paraguariensis e Ocotea odorifera, respectivamente. Estas espécies representavam em 2002-2008, respectivamente, 50,5 e $51,9 \%$ do total da área basal.

As espécies que mais perderam em dominância no período foram: Prunus brasiliensis (-12\%), Styrax leprosus $(-12,1)$, Ilex paraguariensis $(-10,7)$, Myrsine umbellata $(-9,5)$ e Vernonanthura petiolares (-9). Já as espécies que mais ganharam em dominância foram: Araucaria angustifolia $(34,2 \%)$, Ocotea porosa (12,2\%), Ocotea odorifera $(6,6 \%)$, Cedrela fissilis (6,4\%) e Coussarea contracta $(4,1 \%)$.

De acordo com a análise ecofisiológica, a área basal está concentrada e vem aumentando no grupo das espécies secundárias tardias, com 70,3 e $71,7 \%$ do total para os anos de medição, seguido das secundárias iniciais com 22 e 21,3\%; pioneiras com 5,9 e 4,8\%; e indeterminadas com 1,6 e 1,7\%. Este ganho relativo do grupo das secundárias tardias deve-se ao ingresso de novas espécies e indivíduos nessa categoria, mas, principalmente, do incremento em diâmetro de indivíduos pré-existentes de espécies como araucária e imbuia, citadas anteriormente. Assim, visualmente o fragmento representa as condições naturais da Floresta Ombrófila Mista com a Araucaria angustifolia, seguida das espécies da família Lauraceae e a Ilex paraguariensis como dominantes.

\section{Frequência}

Apesar da perda de indivíduos (densidade total) na área estudada, observou-se um ganho em frequência absoluta, devido à ocorrência de novas mais ganharam em frequência foram: Casearia 
TABELA 2: Resultados de densidade obtidos em trabalhos realizados em Floresta Ombrófila Mista.

TABLE 2: Density results obtained in researches performed in Mixed Rain Forest.

\begin{tabular}{|c|c|c|c|c|c|c|c|c|c|c|c|}
\hline \multirow{3}{*}{$\begin{array}{c}\text { Autor } \\
\\
1\end{array}$} & \multicolumn{9}{|c|}{ Densidade/medição } & \multirow{3}{*}{$\begin{array}{c}\mathrm{DI} \\
(\mathrm{cm})\end{array}$} & \multirow{3}{*}{$\begin{array}{r}\text { A A } \\
\text { (ha) }\end{array}$} \\
\hline & \multicolumn{2}{|c|}{$\mathrm{N} / \mathrm{ha}$} & \multirow{2}{*}{$\begin{array}{c}\% / \\
\text { ano } \\
\end{array}$} & \multicolumn{2}{|c|}{ Espécies (\%) } & \multicolumn{2}{|c|}{ Famílias (\%) } & \multirow{2}{*}{ 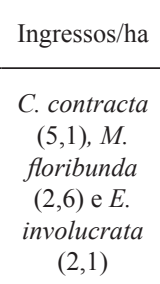 } & \multirow{2}{*}{ 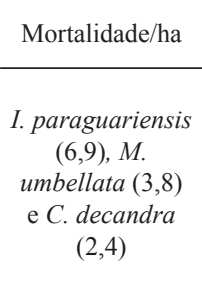 } & & \\
\hline & 581 & 567 & & $\begin{array}{l}\text { I. } \\
\text { paraguariensis } \\
(10,3), \quad O . \\
\text { odorifera }(8,9) \text {, } \\
\text { A. angustifolia } \\
(7,2)\end{array}$ & $\begin{array}{l}\text { I. paraguariensis } \\
(9,4), O . \\
\text { odorifera }(9,2), A \text {. } \\
\text { angustifolia }(7,4)\end{array}$ & $\begin{array}{c}\text { Lauraceae, } \\
\text { Aquifoliaceae, } \\
\text { Salicaceae, } \\
\text { Myrtaceae e } \\
\text { Araucariaceae } \\
(64,4)\end{array}$ & $\begin{array}{c}\text { Lauraceae, } \\
\text { Aquifoliaceae, } \\
\text { Salicaceae, } \\
\text { Myrtaceae e } \\
\text { Araucariaceae } \\
(65,5)\end{array}$ & & & & \\
\hline 2 & 698 & 678 & $-0,36$ & $\begin{array}{c}M . \\
\text { elaeagnoides } \\
(11,8), C . \\
\text { xanthocarpa } \\
(7,7) \text { e } E . \\
\text { uniflora }(6,4)\end{array}$ & $\begin{array}{l}\text { M. elaeagnoides } \\
(11,6), C . \\
\text { xanthocarpa }(8,4) \\
\text { e E. uniflora }(6,2)\end{array}$ & $\begin{array}{c}\text { Myrtaceae, } \\
\text { Sapindaceae, } \\
\text { Lauraceae, } \\
\text { Euphorbiaceae } \\
\mathrm{e} \\
\text { Aquifoliaceae } \\
(66) \\
\end{array}$ & $\begin{array}{c}\text { Myrtaceae, } \\
\text { Sapindaceae, } \\
\text { Lauraceae, } \\
\text { Euphorbiaceae } \\
\text { e Aquifoliaceae } \\
(66,2)\end{array}$ & $\begin{array}{c}C . \\
\text { xanthocarpa } \\
(3,2), M . \\
\text { miersiana } \\
(1,4), \text { e } M . \\
\text { tenella }(0,8)\end{array}$ & $\begin{array}{c}\text { S. leprosus }(6,2) \text {, } \\
\text { M. pungens }(4) \mathrm{e} \\
\text { M.elaeagnoides } \\
(3,8)\end{array}$ & 9,5 & 5 \\
\hline 3 & 544 & 909 & 6,09 & $\begin{array}{l}\text { L. brasiliensis } \\
(13,4), C \text {. } \\
\text { dinisii }(6,5) \text { e } I . \\
\text { theezans }(4)\end{array}$ & $\begin{array}{l}\text { L. brasiliensis } \\
(17,5), M . \\
\text { elaeagnoides }(5,6) \\
\text { e } C \text {. dinisii }(4,9)\end{array}$ & $\begin{array}{l}\text { Anacardiaceae, } \\
\text { Aquilofolia- } \\
\text { ceae, } \\
\text { Lauraceae, } \\
\text { Sapindaceae } \\
\text { e Myrtaceae } \\
(49,5)\end{array}$ & $\begin{array}{l}\text { Anacardiaceae, } \\
\text { Lauraceae, } \\
\text { Aquifoliaceae, } \\
\text { Myrtaceae e } \\
\text { Clethraceae } \\
(52,9)\end{array}$ & $\begin{array}{c}L . \\
\text { brasiliensis } \\
(86,1), M . \\
\text { elaeagnoides } \\
(38,5) \text { e } C . \\
\text { scabra }(24,7)\end{array}$ & $\begin{array}{c}\text { C. vernalis } \\
(13,7), \text { Solanum } \\
\text { sp. }(13,5) \text { e } M . \\
\text { loranthoides } \\
(11,5)\end{array}$ & 10 & 0,96 \\
\hline 4 & 427 & 440 & 1,52 & - & - & - & - & - & - & 10 & 8 \\
\hline 5 & 237 & 245 & 0,16 & $\begin{array}{l}\text { A. angustifolia } \\
(41,8), I \text {. } \\
\text { dumosa } \\
(13,1) \text { e } M \text {. } \\
\text { elaeagnoides } \\
\text { (9) }\end{array}$ & $\begin{array}{c}\text { A. angustifolia } \\
(48,9), M \text {. } \\
\text { elaeagnoides }(7,7) \\
\text { e } N . \text { grandiflora } \\
(7,6)\end{array}$ & $\begin{array}{c}\text { Araucariaceae, } \\
\text { Aquifoliaceae, } \\
\text { Lauraceae, } \\
\text { Sapindaceae } \\
\text { e Myrtaceae } \\
(86,2)\end{array}$ & $\begin{array}{l}\text { Araucariaceae, } \\
\text { Lauraceae, } \\
\text { Myrtaceae, Sap- } \\
\text { indaceae Canel- } \\
\text { laceae }(86,2)\end{array}$ & $\begin{array}{c}A . \\
\text { angustifolia } \\
(20,7), N . \\
\text { grandiflora } \\
(8,6) \text { e } C . \\
\text { xanthocarpa } \\
(4,1) \\
\end{array}$ & $\begin{array}{c}\text { I. dumosa } \\
(26,3), I . \\
\text { brevicuspis }(6) \text {, } \\
\text { M. elaeagnoides } \\
(2,4)\end{array}$ & 20 & 9 \\
\hline 6 & 584 & 586 & 0,34 & - & - & - & - & - & - & 10 & 4 \\
\hline 7 & 577 & 611 & 1,96 & $\begin{array}{l}\text { A. angustifolia } \\
(25,9), N \text {. } \\
\text { grandiflora } \\
(9,5) \text { e } I \text {. } \\
\text { paraguariensis } \\
(5,9)\end{array}$ & $\begin{array}{l}\text { A. angustifolia } \\
(24,6), N \text {. } \\
\text { grandiflora }(10) \mathrm{e} \\
\text { I. paraguariensis } \\
\qquad(6,2)\end{array}$ & $\begin{array}{c}\text { Araucariaceae, } \\
\text { Lauraceae, } \\
\text { Myrtaceae, } \\
\text { Aquifoliaceae } \\
\text { e Sapindaceae } \\
(68,9)\end{array}$ & $\begin{array}{c}\text { Araucari- } \\
\text { aceae, Laura- } \\
\text { ceae, Myrtaceae, } \\
\text { Aquifoliaceae } \\
\text { e Sapindaceae } \\
(69,3)\end{array}$ & $\begin{array}{l}\text { N. grandi- } \\
\text { flora }(6,6), I . \\
\text { paraguarien- } \\
\text { sis }(4,3) \text { e } C \text {. } \\
\text { vesiculosum } \\
\quad(3,1)\end{array}$ & $\begin{array}{l}\text { I. dumosa }(2,9) \text {, } \\
\text { Symplocus sp. } \\
(2,9) \text { e L. brasil- } \\
\text { iensis }(1,7)\end{array}$ & 10 & 3,5 \\
\hline
\end{tabular}

Em que: 1. Dados desta pesquisa (Irati, PR.); 2. Moscovich, 2006 (Nova Prata, RS.); 3. Formento, 2004 (Campo Belo do Sul, SC.); 4. Barth Filho, 2002 (General Carneiro, PR.); 5. Schaaf, 2001 (São João do Triunfo, PR.); 6. Durigan, 1999 (São João do Triunfo, PR.); 7. Pizzato, 1999 (São João do Triunfo, PR.); Média = média aritmética excluindo Schaaf (2001); N/ha = Número total de indivíduos por hectare por ano de medição; \%/ano = incremento anual no número de indivíduos por hectare; Espécies/Famílias (\%) = espécies e famílias de maior densidade por ano de medição em percentagem; Ingressos/ha = espécies que mais ingressaram indivíduos por hectare no período; Mortalidade/ha = espécies em que mais morreram indivíduos por hectare no período; DI = diâmetro $(\mathrm{cm})$ mínimo de inclusão; AA = Área amostrada (ha);

espécies e indivíduos de espécies pré-existentes em novas parcelas da floresta, passando de $5304 \mathrm{em}$ 2002 para 5412 em 2008.

Considerando que uma distribuição regular poderia ser quando a frequência está acima de $50 \%$, pode-se dizer que há uma irregularidade, em todos os anos de medição, na distribuição das espécies e seus indivíduos nas parcelas permanentes. Assim, a floresta apresentou valores percentuais de frequência de espécies de 47,4\% em 2002 e em 2008 este valor caiu para 46,3\%. Esta redução na uniformidade de distribuição das espécies de $1,1 \%$ (-0,2\%/ano) pode ser explicada pela ocorrência de 6 novas espécies com apenas 1 indivíduo/espécie, isto é, a ocorrência de apenas 1 indivíduo da espécie em uma das 25 parcelas existentes na área de estudo.

As espécies que mais perderam em frequência no período de 2002 a 2008 foram: Styrax leprosus com -20\% (redução da ocorrência da espécie em 5 parcelas), Roupala brasiliensis (-12\%), Clethra scabra (-8\%), Ilex dumosa (-8\%) e Luehea divaricata (-8\%). Já as espécies que 
TABELA 3: Resultados de dominância obtidos em trabalhos realizados em Floresta Ombrófila Mista. TABLE 3: Dominance results obtained in researches performed in Mixed Rain Forest.

\begin{tabular}{|c|c|c|c|c|c|c|c|}
\hline \multirow{3}{*}{$\begin{array}{c}\text { Autor } \\
\begin{array}{c}\text { Esta pesquisa } \\
(2010)\end{array}\end{array}$} & \multicolumn{7}{|c|}{ Dominância/medição } \\
\hline & \multicolumn{2}{|c|}{$\mathrm{AB} / \mathrm{ha}$} & \multirow{2}{*}{$\begin{array}{c}\% / \\
\text { ano }\end{array}$} & \multicolumn{2}{|c|}{ Espécies (\%) } & \multicolumn{2}{|c|}{ Famílias (\%) } \\
\hline & 28,7 & 30,2 & & $\begin{array}{l}\text { A. angustifolia }(7,1) \mathrm{e} \\
\text { O. porosa }(2,5)\end{array}$ & $\begin{array}{l}\text { A. angustifolia }(7,8) \mathrm{e} \\
\text { O. porosa }(2,8)\end{array}$ & $\begin{array}{c}\text { Lauraceae, } \\
\text { Araucariaceae, } \\
\text { Aquifoliaceae, } \\
\text { Sapindaceae e } \\
\text { Meliaceae }(73,1)\end{array}$ & $\begin{array}{c}\text { Lauraceae, } \\
\text { Araucariaceae, } \\
\text { Aquifoliaceae, } \\
\text { Meliaceae e } \\
\text { Sapindaceae }(74,4)\end{array}$ \\
\hline Schaaf (2001) & 23,5 & 28,5 & 1,01 & $\begin{array}{c}\text { A. angustifolia }(48,1) \\
\text { e M. elaeagnoides } \\
(10,3)\end{array}$ & $\begin{array}{c}\text { A. angustifolia }(57,8) \\
\text { e M. elaeagnoides } \\
(8,7)\end{array}$ & $\begin{array}{c}\text { Araucariaceae, } \\
\text { Lauraceae, } \\
\text { Aquifoliaceae, } \\
\text { Sapindaceae e } \\
\text { Myrtaceae }(90,2)\end{array}$ & $\begin{array}{c}\text { Araucariaceae, } \\
\text { Lauraceae, } \\
\text { Sapindaceae, } \\
\text { Myrtaceae e } \\
\text { Canellaceae }(92,3)\end{array}$ \\
\hline Pizzato (2001) & 32,1 & 33,1 & 0,99 & $\begin{array}{l}\text { A. angustifolia }(49,1) \\
\text { e O.porosa }(6,7)\end{array}$ & $\begin{array}{l}\text { A. angustifolia }(49,4) \\
\text { e O.porosa }(6,5)\end{array}$ & $\begin{array}{c}\text { Araucariaceae, } \\
\text { Lauraceae, Sapindaceae } \\
\text { e Canellaceae (72) }\end{array}$ & $\begin{array}{c}\text { Araucariaceae, } \\
\text { Lauraceae, } \\
\text { Sapindaceae e } \\
\text { Euphorbiaceae (72) }\end{array}$ \\
\hline $\begin{array}{l}\text { Moscovich } \\
\text { (2006) }\end{array}$ & 30,8 & 33,8 & 1,22 & $\begin{array}{l}\text { M. elaeagnoides } \\
(12,8) \text { e } N \text {. } \\
\text { megapotamica }(6,9)\end{array}$ & $\begin{array}{c}\text { M.elaeagnoides }(12,6) \\
\text { e } N . \text { megapotamica } \\
(7,5)\end{array}$ & $\begin{array}{c}\text { Myrtaceae, } \\
\text { Sapindaceae, Lauraceae, } \\
\text { Araucariaceae e } \\
\text { Euphorbiaceae }(63,4)\end{array}$ & $\begin{array}{c}\text { Myrtaceae, } \\
\text { Sapindaceae, } \\
\text { Lauraceae, } \\
\text { Araucariaceae e } \\
\text { Euphorbiaceae }(63,7)\end{array}$ \\
\hline $\begin{array}{l}\text { Formento et al. } \\
\text { (2004) }\end{array}$ & 19,2 & 28,2 & 4,24 & $\begin{array}{l}\text { L. brasiliensis }(13,5) \\
\text { e I. theezans }(5,3)\end{array}$ & $\begin{array}{l}\text { L. brasiliensis }(17,7) \text { e } \\
\text { M. elaeagnoides }(5,9)\end{array}$ & $\begin{array}{c}\text { Anacardiaceae, } \\
\text { Aquifoliaceae, } \\
\text { Lauraceae, Myrtaceae e } \\
\text { Sapindaceae }(49,2)\end{array}$ & $\begin{array}{l}\text { Anacardiaceae, } \\
\text { Lauraceae, } \\
\text { Aquifoliaceae, } \\
\text { Clethraceae e } \\
\text { Myrtaceae }(52,7)\end{array}$ \\
\hline${ }^{1}$ Média & 27,7 & 31,3 & 1,83 & & & & \\
\hline
\end{tabular}

Em que: ${ }^{1}=$ média aritmética excluindo Schaaf (2001), AB/ha = área basal total por hectare por ano de medição, \%/ ano = incremento anual de área basal em percentagem, Espécies $(\%)=$ espécies dominantes nos anos de medição em percentagem da área basal total por hectare, Famílias (\%) = Famílias botânicas dominantes nos anos de medição em percentagem da área basal total por hectare.

TABELA 4: Espécies presentes em 100\% das parcelas permanentes e suas alterações.

TABLE 4: Species present in $100 \%$ of the permanent sample plots and their changes.

\begin{tabular}{|c|c|c|}
\hline \multirow{2}{*}{ Espécie } & \multicolumn{2}{|c|}{ Ano de medição } \\
\hline & 2002 & 2008 \\
\hline Araucaria angustifolia & - & - \\
\hline Campomanesia xanthocarpa & & • \\
\hline Casearia decandra & • & • \\
\hline Cedrela fissilis & - & • \\
\hline Coussarea contracta & & - \\
\hline Dalbergia frutescens & $\bullet$ & • \\
\hline Eugenia involucrata & & • \\
\hline Ilex paraguariensis & • & • \\
\hline Ilex theezans & • & - \\
\hline Mosiera prismática & & • \\
\hline Myrcia hebepetala & • & • \\
\hline Myrsine umbellata & • & • \\
\hline Nectandra grandiflora & - & - \\
\hline Nectandra megapotamica & & - \\
\hline Ocotea diospyrifolia & - & \\
\hline Ocotea puberula & - & • \\
\hline Prunus brasiliensis & • & • \\
\hline Psychotria vellosiana & - & - \\
\hline
\end{tabular}


lasiophylla com 36\% (aumento de ocorrência da espécie em 9 parcelas), Ocotea corymbosa (24\%), Myrcia lajeana (16\%), Rudgea jasminoides (12\%) e Maytenus grandiflorus (12\%).

A Tabela 4 descreve as espécies que estavam distribuídas em todas as 25 parcelas, com frequência relativa individual máxima de 1,89 e $1,85 \%$ para os anos de 2002 (13 espécies) e 2008 (17 espécies), respectivamente.

As 12 espécies presentes no período de medição, indicam que as famílias Araucariaceae, Aquifoliaceae, Fabaceae-Faboideae, Lauraceae, Meliaceae, Myrsinaceae, Myrtaceae, Rosaceae, Rubiaceae e Salicaceae apresentaram distribuição aleatória e homogênea na floresta, com pelo menos um indivíduo, de uma mesma espécie, em cada parcela. Esta informação mostra a plasticidade de tais espécies e que os solos podem possuir características semelhantes. Outro fator a ser considerado é que nem só as espécies mais densas apresentaram pelo menos 1 indivíduo por parcela.

$\mathrm{O}$ número de apenas 12 espécies estarem presentes em $100 \%$ das parcelas não pode ser considerado como baixo quando comparado a trabalhos de Formento et al. (2004) e Sanquetta et al. (2001), os quais relataram que nenhuma espécie estava presente em $100 \%$ das parcelas medidas. Já Schaaf (2001) encontrou apenas uma espécie (Araucaria angustifolia) distribuída homogeneamente na área amostrada. Apesar de Formento et al. (2004) terem utilizado parcelas de 0,06 ha, o alto valor no número de espécies em $100 \%$ das parcelas encontrado neste trabalho pode ter sido influenciado principalmente pelo alto grau de conservação da área e estágio maduro da floresta o qual favorece a diversidade e ocorrência das espécies em novas parcelas.

A análise ecofisiológica corrobora com a influência do estádio sucessional da floresta para uma distribuição uniforme das espécies, principalmente secundárias tardias. No período de 2002 a 2005, das 13 espécies presentes em $100 \%$ das parcelas $53,8 \%$ delas eram pertencentes ao grupo ecofisiológico das secundárias tardias, $38,5 \%$ eram pertencentes às secundárias iniciais e $7,7 \%$ de espécies indeterminadas. Já para o ano de 2008, das 17 espécies presentes 58,8\%, 29,4\% e $11.7 \%$ delas eram pertencentes ao grupo ecofisiológico das secundárias tardias, secundárias iniciais e de espécies indeterminadas, respectivamente. As espécies pioneiras ocorreram em reboleiras em todas as medições.

\section{Valor de importância absoluto (VI abs.)}

Observa-se que houve um aumento do valor de importância absoluto (VI abs. $=300)$ de 0,61 (VI rel. $=0,03 \% /$ ano), das 5 principais espécies no período estudado, passando de $95,8(31,9 \%)$ em 2002 para 96,4 (32,1\%) em 2008, conforme Figura 1.

As cinco espécies que apresentaram os maiores valores de importância absolutos (VI abs.), ou seja, as espécies mais importantes ecologicamente para o período de medição foram: Araucaria angustifolia com 33,7 e 35,2; Ilex paraguariensis com 17,9 e 16,3 e algumas espécies da família Lauraceae (canelas em geral) como: Ocotea odorifera com 15,8 e 16,3; Nectandra grandiflora com 14,6 e 14,3 e a Ocotea porosa com 13,7 e 14,2 .

No período de 2002 a 2008, uma tendência foi comprovada, a Araucaria angustifolia é a espécie mais importante do fragmento estudado e sua importância ecológica aumenta à taxa de VI rel. $=0,08 \% /$ ano. Para isso a espécie tornou-se mais densa (5 indivíduos ingressos), dominante (incremento de área basal de $0,74 \mathrm{~m}^{2} / \mathrm{ha}$ ) e permaneceu presente (frequência) em $100 \%$ das

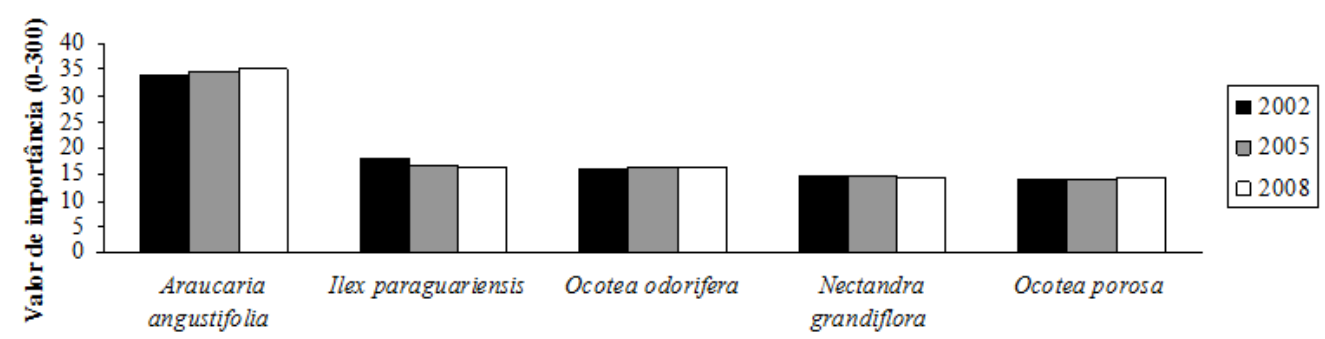

FIGURA 1: Alteração do valor de importância absoluto das cinco espécies mais importantes de 2002-2008.

FIGURE 1: Change of absolute importance value of five most important species of 2002-2008. 


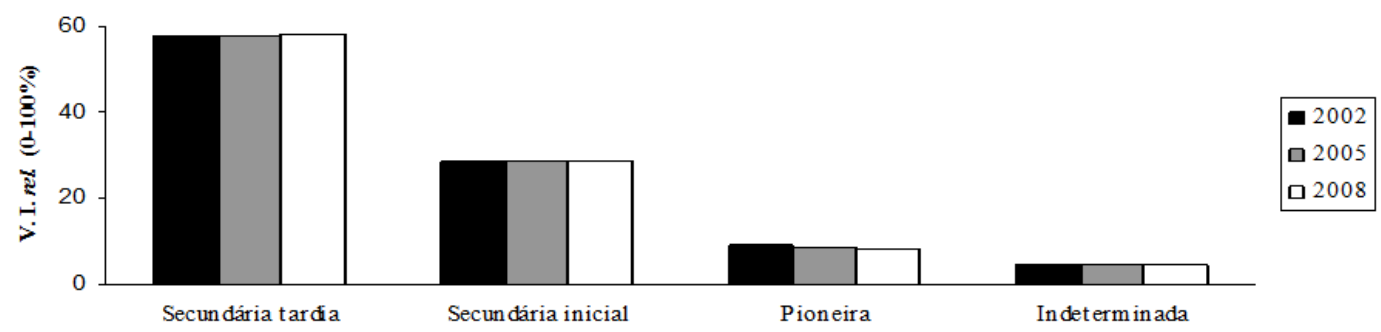

FIGURA 2: Alteração do valor de importância relativo nos grupos ecofisiológicos nos anos de medição. FIGURE 2: Change of relative importance value in the ecophyisiological groups in the years of measurement.

parcelas permanentes. Este resultado assemelha-se ao encontrado por Schaaf (2001) o qual registrou que a Araucaria angustifolia foi a espécie mais importante ecologicamente e teve uma taxa de VI rel. $=0,26 \% /$ ano no período de 21 anos, ingressando 186 indivíduos, aumentando sua dominância em $5,16 \mathrm{~m}^{2} /$ ha e permanecendo presente em todas as parcelas amostradas. Já Formento et al. (2004) encontraram a espécie Lithraea brasiliensis como a mais importante com taxa de VI rel.=0,25\%/ano.

Tendência contrária a da Araucaria angustifolia, apresentou a Ilex paraguariensis, que vem perdendo indivíduos e tornando-se menos densa e dominante, porém, continua presente nas 25 parcelas da área (100\% frequência). Esta espécie em 2002 apresentava um valor de importância absoluto de 17,8 e em 2008 de 16,3, isto representa uma redução de $0,08 \%$ /ano no valor de importância relativo. Assim, seu comportamento assemelha-se a uma secundária inicial e não a uma secundária tardia como imaginado.

Entre 2002 e 2008, as espécies que mais perderam em valor de importância absoluto foram: Ilex paraguariensis com -1,5, Styrax leprosus $(-1,0)$, Myrsine umbellata (-0,9), Prunus brasiliensis $(-0,7) \mathrm{e}$ Vernonanthura petiolaris $(-0,7)$. No mesmo período, as espécies que mais ganharam foram: Araucaria angustifolia com 1,5, Coussarea contracta $(1,4)$, Casearia lasiophylla $(0,8)$, Casearia sylvestris $(0,6)$ e Eugenia involucrata $(0,6)$.

O cálculo dos valores de importância relativo dos grupos ecofisiológicos para 20022008 encontrou índices de 8,9 e 8,3 para as pioneiras; para as secundárias iniciais 28,7 e 28,6 ; para as secundárias tardias 57,5 e 58,4 ; e para as indeterminadas de 4,7 e 4,8; conforme Figura 2.

Nota-se que, para o período estudado, as espécies secundárias tardias estão numa ascendência quanto a sua importância em relação às espécies secundárias iniciais e pioneiras. Este aumento de 3,3 do valor de importância absoluto das espécies secundárias tardias segue uma direção contrária ao índice de valor de importância das espécies secundárias iniciais e pioneiras, que apresentaram uma redução de 1,3 e 1,8, respectivamente. Estes percentuais são indícios do estádio sucessional avançado da floresta, o qual favorece o aumento da riqueza e estabilidade do ecossistema.

\section{CONCLUSÕES}

- A densidade diminuiu 0,39\%/ano, principalmente devido à mortalidade de indivíduos de pequeno diâmetro, os quais sofreram com a competição intra e interespecífica por nutrientes, espaço e principalmente luz;

- As espécies secundárias tardias Ilex paraguariensis, Ocotea odorifera, Araucaria angustifolia, Nectandra grandiflora e Casearia decandra caracterizaram a fitofisionomia da floresta;

- Ilex paraguariensis foi a espécie que apresentou maior mortalidade de indivíduos, enquanto que a Coussarea contracta foi a que teve o maior ingresso. A grande maioria dos indivíduos ingressos no período pertence ao grupo ecofisiológico das secundárias tardias e iniciais, o que sugere uma floresta com estádio avançado de sucessão ecológica e estrutura estável;

- O aumento na dominância (área basal) de 0,87\%/ano indica que o estoque está em crescimento apesar da mortalidade de 340 indivíduos na floresta. Este incremento decorre do crescimento em diâmetro de indivíduos pré-existentes de Araucaria angustifolia e Ocotea porosa e ao ingresso de indivíduos de 
Coussarea contracta;

- Apesar da grande riqueza de espécies encontradas na área estudada, a frequência indica que apenas $15 \%$ delas encontram-se distribuídas uniformemente na área, o que parece ser uma característica dessa tipologia florestal;

- A araucária é a espécie mais importante ecologicamente, segundo os critérios de densidade, dominância e frequência relativos sintetizados no valor de importância e, com o passar dos anos, este índice aumentou a uma taxa anual de $0,08 \%$;

- O índice de valor de importância sugere que a floresta tem se tornado mais madura a cada medição, com a grande maioria de espécies e indivíduos $(90 \%)$ arbóreos pertencentes a espécies secundárias tardias;

- A floresta mostra-se totalmente recuperada, em condições naturais de desenvolvimento e sem evidências de ações antrópicas realizadas no passado, bastante diversificada, porém, com a grande maioria de seus indivíduos pertencentes a poucas espécies de poucas famílias botânicas,o que parece ser uma característica desta formação florestal.

\section{REFERÊNCIAS BIBLIOGRÁFICAS}

ARCE, J. E. FlorExel, versão 3.2.1. Suplemento para Microsoft Excel®. Curitiba, 2007.

BARTH, N. F. Monitoramento do crescimento e da produção e floresta ombrófila mista com uso de parcelas permanentes. 2002. 86 f. Dissertação (Mestrado em Manejo Florestal) - Universidade Federal do Paraná, Curitiba, 2002.

BITTENCOURT, J. V. M. et al. Conservation, management and sustainable use of Araucaria angustifolia genetic resources in Brazil. In: VINCENTI, B.; W. AMARAL, N.;MEILLEUR, B. (eds), Challenges in managing forest genetic resources for livelihoods. Examples from Argentina and Brazil. Rome, Italy: International Plant Genetic Resources Institute, 2004. p. 133-148. CARVALHO, P. E. R. Espécies florestais brasileiras. Brasília: Embrapa Florestas, 2003, $1039 \mathrm{p}$.

CASTElla, P. R.; BRITEZ, R. M. de. A floresta com araucária no Paraná: conservação e diagnóstico dos remanescentes florestais. Fundação de Pesquisas Florestais do Paraná. Brasília: Ministério do Meio Ambiente, 2004, 236 p.
CATHARINO, E. L. M. et al. Aspectos da composição e diversidade do componente arbóreo das florestas da Reserva Florestal do Morro Grande, Cotia, SP. Biota Neotrop. May/Aug 2006 v. 6 n. 2, http://www.biotaneotropica.org.br/v6n2/pt/ abstract?article+bn00306022006. ISSN 1676-0603. DURIGAN, M. E. Florística, dinâmica e análise protéica de uma Floresta Ombrófila Mista em São João do Triunfo - PR. 1999. 125 f. Dissertação (Mestrado em Manejo Florestal) - Setor de Ciências Agrárias, Universidade Federal do Paraná, Curitiba, 1999.

FIGUEIREDO FILHO, A. et al. Crescimento sazonal em diâmetro de 16 espécies de uma Floresta Ombrófila MistanaFloresta Nacional de Irati,Paraná, Brazil. In: CONGRESSO LATINOAMERICANO IUFRO, 2., 2006, La Serena. Anales ... La Serena: IUFRO-INFOR, 2006. v.1.

FONSECA, R. C. B.; RODRIGUES, R. R.; Análise estrutural e aspectos do mosaico sucessional de uma floresta semi-decídua em Botucatu, SP. Scientia Forestalis, Piracicaba, n. 57, p. 27-43, jun. 2000. FORMENTO, S.; SCHORN, L. A.; RAMOS, R. Dinâmica Estrutural Arbórea De Uma Floresta Ombrófila Mista Em Campo Belo Do Sul, Sc. Cerne, Lavras, v. 10, n. 2, p. 196-212, jul./dez. 2004. GANDOLFI, S.; LEITÃO FILHO, H.; BEZERRA, C. L. F. Levantamento florístico caráter sucessional das espécies arbustivo-arbóreas de uma floresta mesófila semi-decídua no município de Guarulhos - SP. Revista Brasileira de Botânica, v. 55, n. 4, p. 753-767, 1995.

ISERNHAGEN, I. et al. Listagem de espécies arbustivo-arbóreas citadas nos trabalhos de fitossociologia florestal no Paraná, Brasil: uma contribuição aos programas de recuperação de áreas degradadas (RAD) ${ }^{\mathbf{1}}$. In: A fitossociologia florestal no Paraná e os programas de recuperação de áreas degradadas: uma avaliação. 2001. 175 f. Dissertação (Mestrado em Botânica) - Depto. De Botânica da Universidade Federal do Paraná. Curitiba, 2001.

IBGE. Mapa de Biomas do Brasil e o Mapa de Vegetação do Brasil. Disponível em: http://www. ibge.gov.br/home/presidencia/noticias/noticia visualiza.php?id_noticia=169. Acessado em: 15 fev. 2010.

IBGE. Manual Técnico da Vegetação Brasileira. Rio de Janeiro, 1992. 92 p. ((Manuais técnicos de geociências, n.1)

LAMPRECHT, H. Silvicultura nos trópicos: ecossistemas florestais e respectivas espécies 
arbóreas:possibilidadesemétodosdeaproveitamento sustentado. Eschborn: GTZ, 1990. 343 p. MANTOVANI, M. et al. Diversidade de espécies e estrutura sucessional de uma formação secundária da floresta ombrófila densa. Scientia Forestalis, $n$. 67, p. 14-26, abr. 2005.

MAZZA, C. A. S.; MAZZA, M. C. M.; SANTOS, J. E. SIG aplicado à caracterização ambiental de uma unidade de conservação Floresta Nacional de Irati, Paraná. In: SIMPÓSIO BRASILEIRO DE SENSORIAMENTO REMOTO, 12., 2005, Goiânia. Anais ... Goiânia: INPE, 2005.p. 2251-2258. MOSCOVICH, F. A. Dinâmica de crescimento de uma Floresta Ombrófila Mista em Nova Prata, RS. 2006. 130 f. Tese (Doutorado em Ciências Florestais) - Programa de Pós-Graduação em Engenharia Florestal, Universidade Federal de Santa Maria, 2006.

OLIVEIRA, R. J.; MANTOVANI, W.; MELO, M. M. R. F. Estrutura do componente arbustivo-arbóreo da floresta atlântica de encosta, Peruíbe, SP. Acta botânica Brasilica, v. 15, n. 3, p. 391-412, 2001.

PIZATTO, W. Avaliação biométrica da estrutura e da dinâmica de uma Floresta Ombrófila Mista em São João do Triunfo, PR.: 1995 a 1998. 1999. 172 f. Dissertação (Mestrado em Engenharia Florestal) - Setor de Ciências Agrárias, Universidade Federal do Paraná, Curitiba, 1999.

RODE, R. Avaliação florística e estrutural de uma floresta ombrófila mista e de uma vegetação arbórea estabelecida sob um povoamento de Araucaria angustifolia de 60 anos. 2008. $132 \mathrm{f}$. Dissertação (Mestrado em Manejo Florestal) Setor de Ciências Agrárias, Universidade Federal do Paraná, Curitiba, 2008.
SANQUETTA, C. R. et al. Dinâmica da estrutura horizontal de um fragmento de Floresta Ombrófila Mista no Centro-Sul do Paraná. Revista Ciências Exatas e Naturais, v. 3, n. 1, p. 44-57, Jan/Jun 2001. SANTOS, J. H. S. et al. Distinção de grupos ecológicos de espécies florestais por meio de técnicas multivariadas. R. Árvore, Viçosa, v.28, n.3, p. 387-396, 2004.

SAWCZUK, A. R.; Florística e estrutura horizontal no período 2002-2008 de um fragmento de Floresta Ombrófila Mista no Centro-Sul do Estado do Paraná, 2009. 139 f. Dissertação (Mestrado em Engenharia Florestal) Setor de Ciências Agrárias, Universidade Estadual do Centro-Oeste, Irati, 2009.

SCHAAF, L. B.; Florística, estrutura e dinâmica no período 1979-2000 de uma Floresta Ombrófila Mista localizada no Sul do Paraná, 2001. 119 f. Dissertação (Mestrado em Engenharia Florestal) Setor de Ciências Agrárias, Universidade Federal do Paraná, Curitiba, 2001.

SCOLFORO, J. R. Inventário Florestal. Lavras: ESAL/FAEPE, 1993. 228 p.

SILVA, A. J. C. et al. Banco de Sementes em Floresta Ombrófila Mista Aluvial - Municípios de Araucaria e Balsa Nova. In: CONGRESSO DE ECOLOGIA DO BRASIL, 8., 2007, Caxambú. Anais ... Caxambú, 2007.

SOUZA, V.C.; LORENZI, H. Botânica sistemática: guia ilustrado para identificação das famílias de Angiospermasnaflorabrasileira,baseadoemAPG II. Nova Odessa: Instituto Plantarum, 2005. 639 p. ZIN, M. T. Developing a Scientific Basis for Sustainable Management of Tropical Forest Watershed: Cases Studies of Myanmar.2005. 282 p. Tese (A dissertation to obtain the degree of Doctor) Faculty of the Forest Science and Forest Ecology, George- August-University, Göttingen, 2005. 